\title{
Article \\ A Metagenomic Nanopore Sequence Analysis Combined with Conventional Screening and Spectroscopic Methods for Deciphering the Antimicrobial Metabolites Produced by Alcaligenes faecalis Soil Isolate MZ921504
}

\author{
Mohamed A. Eltokhy ${ }^{1}{ }^{(D}$, Bishoy T. Saad ${ }^{2}{ }^{(D}$, Wafaa N. Eltayeb $^{1}{ }^{(D}$, Mona R. El-Ansary $^{3}$, \\ Khaled M. Aboshanab ${ }^{4, *(D)}$ and Mohamed S. E. Ashour ${ }^{5}$
}

1 Department of Microbiology, Faculty of Pharmacy, Misr International University (MIU), Cairo 19648, Egypt; mohammad.ashraf@miuegypt.edu.eg (M.A.E.); wafaa.eltayeb@miuegypt.edu.eg (W.N.E.)

2 Department of Bioinformatics, HITS Solutions Co., Cairo 11765, Egypt; bishoyth@hitssolutions.com

3 Department of Biochemistry, Modern University for Technology and Information (MTI), Cairo 12055, Egypt; Mona.El-Ansary@pharm.mti.edu.eg

4 Department of Microbiology and Immunology, Faculty of Pharmacy, Ain Shams University, Organization of African Unity St., Cairo 11566, Egypt

check for updates

Citation: Eltokhy, M.A.; Saad, B.T.; Eltayeb, W.N.; El-Ansary, M.R.; Aboshanab, K.M.; Ashour, M.S.E. A Metagenomic Nanopore Sequence Analysis Combined with Conventional Screening and Spectroscopic Methods for Deciphering the Antimicrobial Metabolites Produced by Alcaligenes faecalis Soil Isolate MZ921504 Antibiotics 2021, 10, 1382. https://doi.org/10.3390/ antibiotics10111382

Academic Editor: Manuel Simões

Received: 25 October 2021

Accepted: 9 November 2021

Published: 11 November 2021

Publisher's Note: MDPI stays neutral with regard to jurisdictional claims in published maps and institutional affiliations.

Copyright: (c) 2021 by the authors. Licensee MDPI, Basel, Switzerland. This article is an open access article distributed under the terms and conditions of the Creative Commons Attribution (CC BY) license (https:/ / creativecommons.org/licenses/by/ $4.0 /)$.
Department of Microbiology and Immunology, Faculty of Pharmacy, Al-Azhar University, Cairo 11651, Egypt; seifashour@hotmail.com

* Correspondence: aboshanab2012@pharma.asu.edu.eg; Tel.: +20-(202)-28429040; Fax: +20-(202)-24051107

Abstract: The continuous development of multidrug resistance pathogens with limited therapeutic options has become a great problem globally that impose sever health hazards. Accordingly, searching for of new antimicrobials became an urgent demand and great challenge. Soil significantly have been associated with several species that are antibiotic producers. In this study, combination of conventional screening methods with Liquid chromatography- Mass spectroscopy (LC/MS) and metagenomic nanopore sequence analysis have been conducted for the deciphering the active metabolites produced by soil isolate(s). Preliminary soil screening resulted in a Gram-negative isolate identified via 16S ribosomal RNA as Alcaligenes faecalis isolate MZ921504 with promising antimicrobial activities against wide range of MDR gram-positive and gram-negative pathogens. The LC/MS analysis of the metabolites of A. faecalis isolate MZ921504 confirmed the presence of ectoine, bacillibactin, quinolobactin and burkholderic acid. Metagenomics sequence analysis of the soil sample (NCBI GenBank accession PRJNA771993) revealed the presence of conserved biosynthetic gene clusters of ectoine, bacteriocin, bacillibactin, quinolobactin, terpene and burkholderic acid of $A$. faecalis. In conclusion, A. faecalis isolate MZ921504 is a promising source for antimicrobial metabolites. LC/MS spectral analysis and third generation sequencing tools followed by secondary metabolite gene clusters analysis are useful methods to predict the nature of the antimicrobial metabolites.

Keywords: Alcaligenes faecalis; LC/MS; metagenomics; ectoine; bacillibactin; quinolobactin; burkholderic acid

\section{Introduction}

In 2004, the world health organization (WHO) declared that the search for new medicines to combat multidrug resistant (MDR) is the number one area for research that will impact public health [1]. The extensive spread of bacterial resistance became a public health issue that needs fast intervention [2]. The unsatisfactory result in combating MDR could mean a literal return to pre-antibiotic era for many infections [3]. Countries already started protocols to prevent further spread of resistant bacterial strains, with non-consistent results [4]. The alarming rate of MDR made it obligatory to search for new approaches to combat MDR [5]. The natural compounds that are produced from bacteria and fungi are secondary metabolites. Actinomycetaceae, bacterial family, has been associated with 
most of new and old antimicrobials produced by bacteria. The first 30 years of antibiotic discovery, from 1940s to 1970s, was dependent on phenotypic screening which led to the discovery of streptomycin and other antibiotics [6]. A projected approach is searching for new antimicrobial agents from natural sources [5]. The huge diversity of soil serves a great potential for mining novel antimicrobials from soil microbiota [7].

Although bacteria from the soil has been studied for more than a century, but still most soil bacterial $16 \mathrm{~S}$ ribosomal RNA (rRNA) sequence do not match what we have in the GenBank [8]. The advancement in sequence technology made it possible to revisit the path of discovery of new antimicrobials naturally, without revisiting old pathways through trial and error [6]. Developed genetic engineering and genetic learnings together with high throughput detection approaches increases the high probability for novel natural product discovery and production [6].

In the second decade in sequencing, metagenomics analysis was introduced. Metagenomics analysis covers all DNA present in a sample [9]. Metagenomics comprises the sampling of various genomic sequences from a specific community. It has been used solely to microbial habitats. It serves as an impartial platform for microbial diversity and metabolic potential of a microbial community. Metagenomics steered the wheel back to discovery of antimicrobials from natural sources after abandoning this way for some time due to the elevated rediscovery rates of antimicrobials [10]. Bioinformatics analysis and systematic characterization make it possible to explore hidden biosynthetic gene clusters. The culture independent approach contribute to the discovery of malacidins an antimicrobial group that have activity against MRSA [10].

The genus Alcaligenes is known to have antagonistic activity against other microorganisms [11,12]. Alcaligenes faecalis (A. faecalis) is an organism isolated from soil or marine environments that exhibit antibacterial activity against other microorganism, thus it serves as a potential organism for antimicrobial extraction and discovery [11-13]. A. faecalis is Gram negative rod shaped, alkali tolerant and motile [13,14]. It is known to be oxidase and cytochrome oxidase positive, catalase negative, glucose non fermenter, proteolytic and hydrolyze starch [13]. A. faecalis was examined for bacteriocin production by examining inhibitory effect against several microorganisms which were Salmonella, Escherichia, Serratia, Proteus, Staphylococci and Gram-positive aerobic bacilli [15]. In a study conducted by Zahir et al. (2013), A. faecalis was isolated from soil sample and the extracted antimicrobial showed inhibitory effects against both Gram positive and Gram negative. The antimicrobial agent was extracted using solvent extraction method by ethyl acetate and believed to be a non-proteinaceous substance [16].

Few studies were published on the antimicrobial metabolites produced by A. faecalis [17-19]. Therefore, the present study aimed to discover the nature of the antimicrobial metabolites from $A$. faecalis isolate recovered from Egyptian soil by using conventional and chromatographic methods and correlating the obtained results with those of nanopore metagenomics biosynthetic gene clusters analysis which is a novel approach for deciphering the antimicrobial metabolites of soil microbiota.

\section{Results}

\subsection{Screening of the Antimicrobial Activities of the Recovered Bacterial Isolates}

Tables 1 and 2 showed the results of the preliminary screening for the antimicrobial activities of the recovered bacterial isolates. Only eight isolates, coded SS9, SS10, SS11, SS12, SS13, SS14, SS16 and SS17 and six isolates, coded SS9, SS10, SS13, SS14, SS16 and SS17 gave positive results against the tested Gram positive and Gram negative, respectively. None of the recovered isolates gave growth inhibition against the tested Candida isolates. Tables 1 and 2 revealed the inhibition zone of the promising Gram positive Bacillus sp. (coded SS10) and Gram-negative isolate (coded SS17). In this study, the Gram-negative isolate (SS17) was selected for further study since few studies were conducted on the Gram-negative strains that showed antimicrobial activities against wide range of MDR Gram positive and Gram-negative pathogens. 
Table 1. Preliminary screening against Gram positive test organisms.

\begin{tabular}{ccccccc}
\hline \multirow{2}{*}{ Isolate Code } & \multicolumn{7}{c}{ Gram Positive Test Organisms } \\
\cline { 2 - 7 } & SE1 & SE2 & SE3 & VRSA1 & VRSA2 & VRSA3 \\
\hline SS9 & + & - & + & + & - & - \\
SS10 & + & + & + & + & + & + \\
SS11 & - & - & + & - & - & - \\
SS12 & + & + & + & + & + & + \\
SS13 & + & - & + & - & - & - \\
SS14 & - & - & + & + & - & - \\
SS16 & + & + & - & + & + & + \\
SS17 & + & + & + & + & + & + \\
\hline
\end{tabular}

+: inhibits growth, -: no inhibition and SE1, S. epidermidis isolate 1; SE2, S. epidermidis isolate 2; SE3, S. epidermidis isolate 3; VRSA1, vancomycin resistance $S$. aureus isolate 1; VRSA2, vancomycin resistance S. aureus isolate 2; VSRA3, vancomycin resistance $S$. aureus isolate 3.

Table 2. Primary screening against Gram negative test organisms.

\begin{tabular}{ccccccc}
\hline \multirow{2}{*}{ Isolate Code } & \multicolumn{7}{c}{ Gram Negative Test Organisms } \\
\cline { 2 - 7 } & E. coli ATCC 25922 & EC1 & EC2 & KP1 & KP2 & KP3 \\
\hline SS9 & - & + & - & + & - & - \\
SS10 & + & + & + & + & + & + \\
SS13 & - & - & - & + & - & - \\
SS14 & - & - & - & + & - & - \\
SS16 & - & + & - & + & - & - \\
SS17 & + & + & - & + & - & - \\
\hline
\end{tabular}

+: inhibits growth, -: no inhibition. EC1, MDR E. coli isolate 1; EC2; MDR E. coli isolate 2; KP1, MDR K. pneumoniae isolate 1; KP2, MDR K. pneumoniae isolate 2; KP3, MDR K. pneumoniae isolate 3.

\subsection{Molecular Identification}

The16s ribosomal RNA sequencing of the Gram negative isolate coded SS17 revealed 99\% identity to NCBI reference sequence of $A$. faecalis strain 32SR17. Therefore, the isolate coded SS17 was identified as A. faecalis isolate MZ921504. The RNA sequence was deposited in the GenBank under accession number MZ921504.

\subsection{The Antimicrobial Activities of the Extracted Metabolite(s) of A. faecalis Isolate MZ921504}

Table 3 revealed the results of the antimicrobial activity (measured in zone of inhibition) of the A. faecalis isolate MZ921504 of dichloromethane and ethyl acetate solvent extracts.

Table 3. The antimicrobial activity of the of the solvent extracts of A. faecalis isolate MZ921504.

\begin{tabular}{ccc}
\hline \multirow{2}{*}{ Test Organisms } & \multicolumn{2}{c}{ Mean Zone of Inhibition $(\mathbf{m m}) \pm$ SD } \\
\cline { 2 - 3 } & Dichloromethane Extract & Ethyl Acetate Extract \\
\hline S. aureus ATCC 25293 & $13.0 \pm 0.5$ & $16.0 \pm 0.5$ \\
VRSA2 & - & $16.0 \pm 1.0$ \\
KP1 & $12.0 \pm 0.5$ & $17.0 \pm 0.5$ \\
KP2 & - & $17.0 \pm 0.5$ \\
EC1 & $15.0 \pm 0.5$ & $16.0 \pm 1.0$ \\
EC2 & - & $13.0 \pm 0.5$ \\
CA albicans ATCC 10231 & - & $17.0 \pm 1.0$ \\
CA1 & - & - \\
\hline
\end{tabular}

-, absence of inhibition zone. VRSA2, vancomycin resistance S. aureus isolate 2; EC1, MDR E. coli isolate 1; EC2; MDR E. coli isolate 2; KP1, MDR K. pneumoniae isolate 1; KP2, MDR K. pneumoniae isolate 2; CA1, C. albicans clinical isolate 1. 


\subsection{Characterization of the Antimicrobial Metabolite(s)}

\subsubsection{TLC Analysis}

TLC was carried out for ethyl acetate extracts of A. faecalis fermentation product. TLC using solvent system ethyl acetate: methanol (9:1) showed four separated spots. TLC using solvent system ethyl acetate: methylene chloride (9:1) revealed eight separated spots. However, them TLC for solvent system dichloromethane: ethanol (6.5:3.5) showed no significant separation of the spots. Accordingly, the solvent system ethyl acetate: methylene chloride 9:1 was the optimum for better separation of the TLC spots.

\subsubsection{LC/MS Analysis}

Ethyl Acetate Extract of $A$. faecalis

LC/MS was carried on cell free ethyl acetate extract generated 108 peaks in negative ion mode and 109 peaks in positive ion mode illustrated in Figure 1 and each peak had variable masses.

- Negative Ion mode.
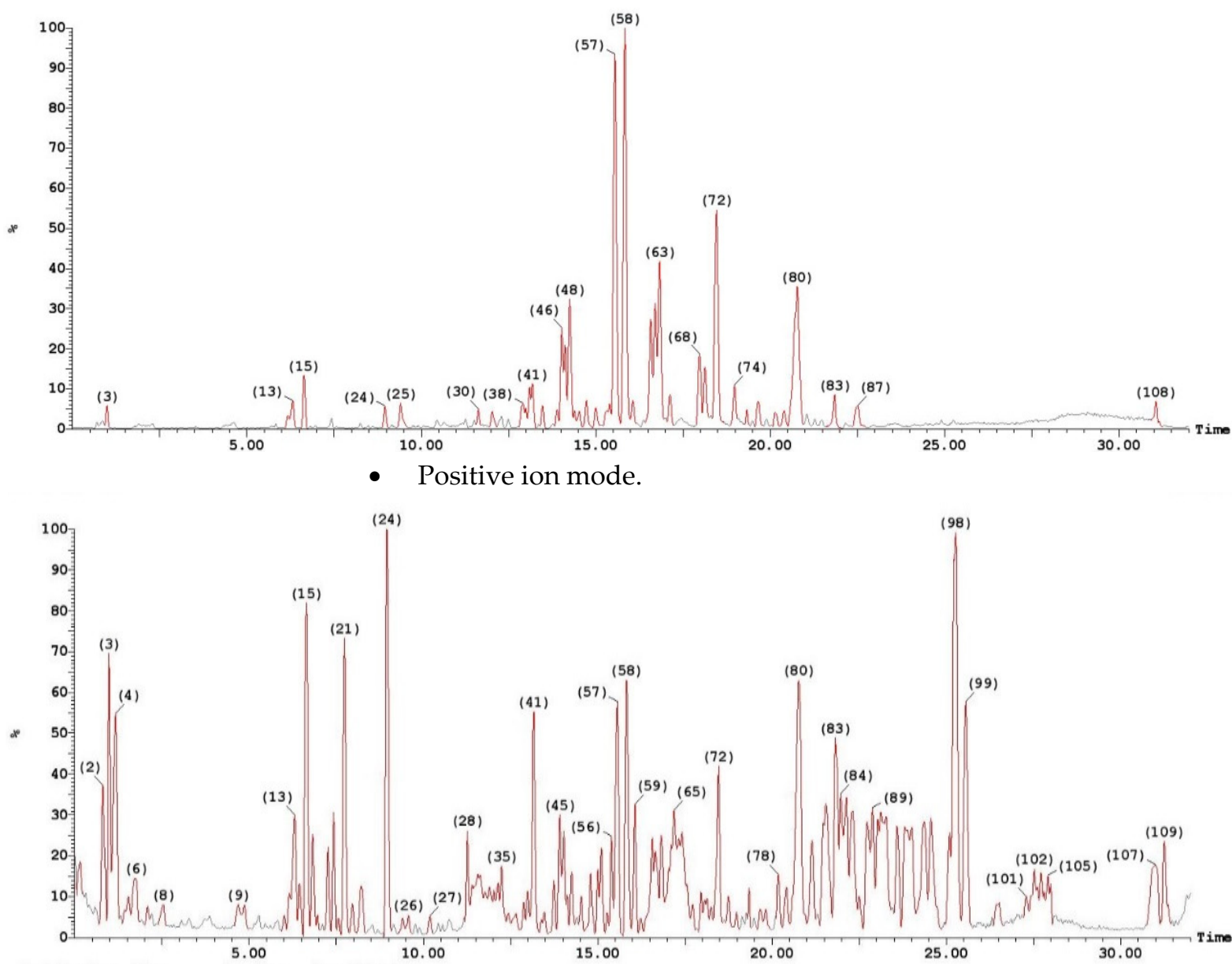

Figure 1. A cell free ethyl acetate extract run on both ESI-MS positive and negative ion mode for antibiotic detection from the isolate $A$. faecalis isolate MZ921504 using XEVO TQD triple quadrupole instrument.

The mass spectra were analyzed for the detection of the secondary metabolite of $A$. faecalis isolate MZ921504 as illustrated in Figure 2. Ectoine was detected at peak 109 at time $31.26 \mathrm{~min}$ with $\mathrm{m} / \mathrm{z}$ 143.94. Bacillibactin was detected at peak 53 at time $15.01 \mathrm{~min}$ with $\mathrm{m} / \mathrm{z}$ 607.5099. Quinolobactin was detected at peak 39 at time $12.99 \mathrm{~min}$ with $\mathrm{m} / \mathrm{z} 219.2302$ and detection of Burkholderic acid at peak 39 at time $12.99 \mathrm{~min}$ with $\mathrm{m} / \mathrm{z} 303.3043$. 


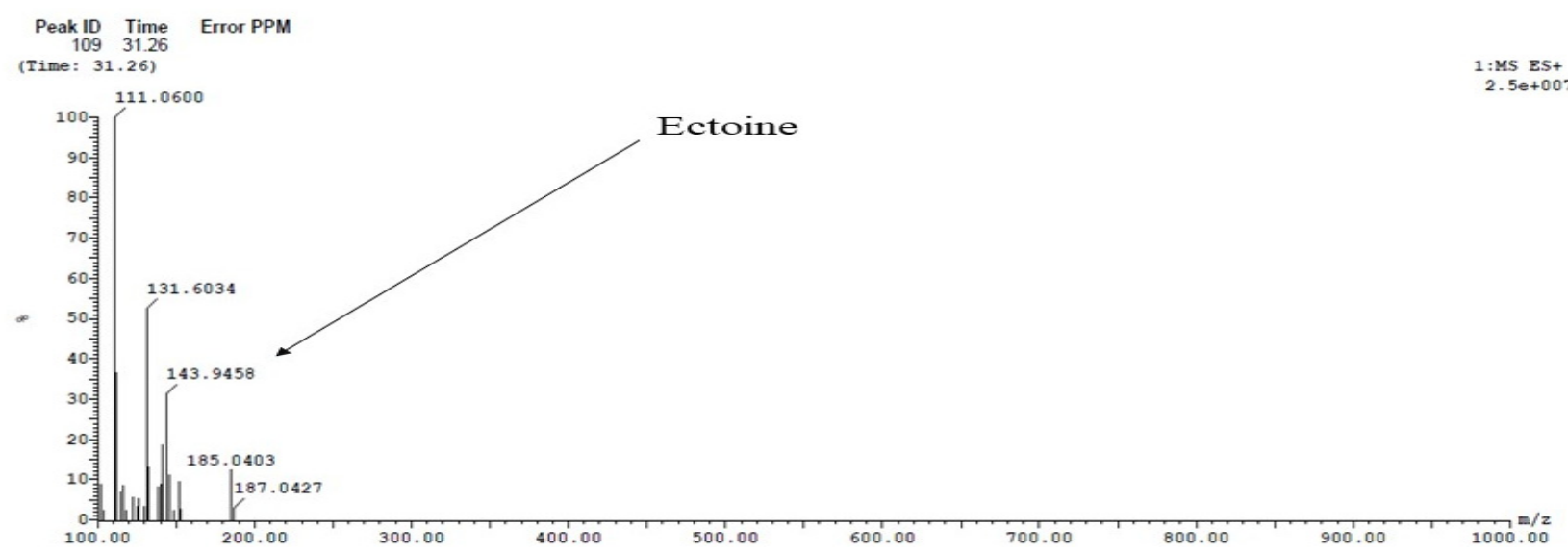

(a)

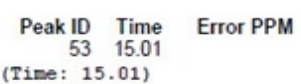

(Tine: 15.01)

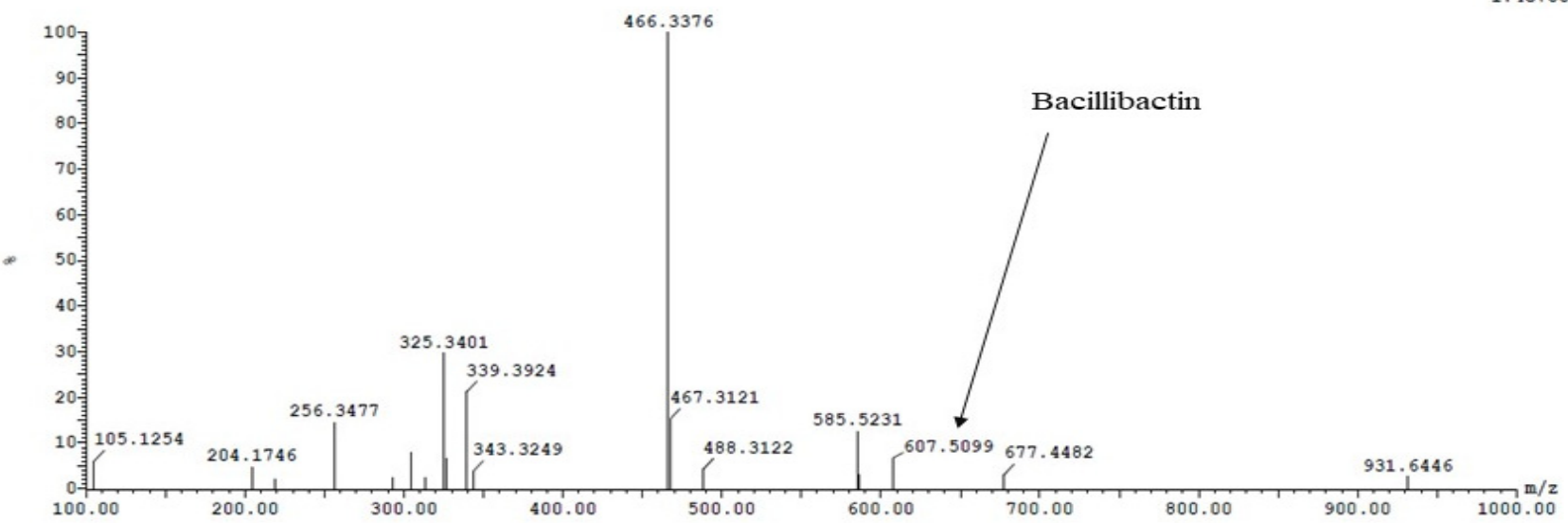

(b)

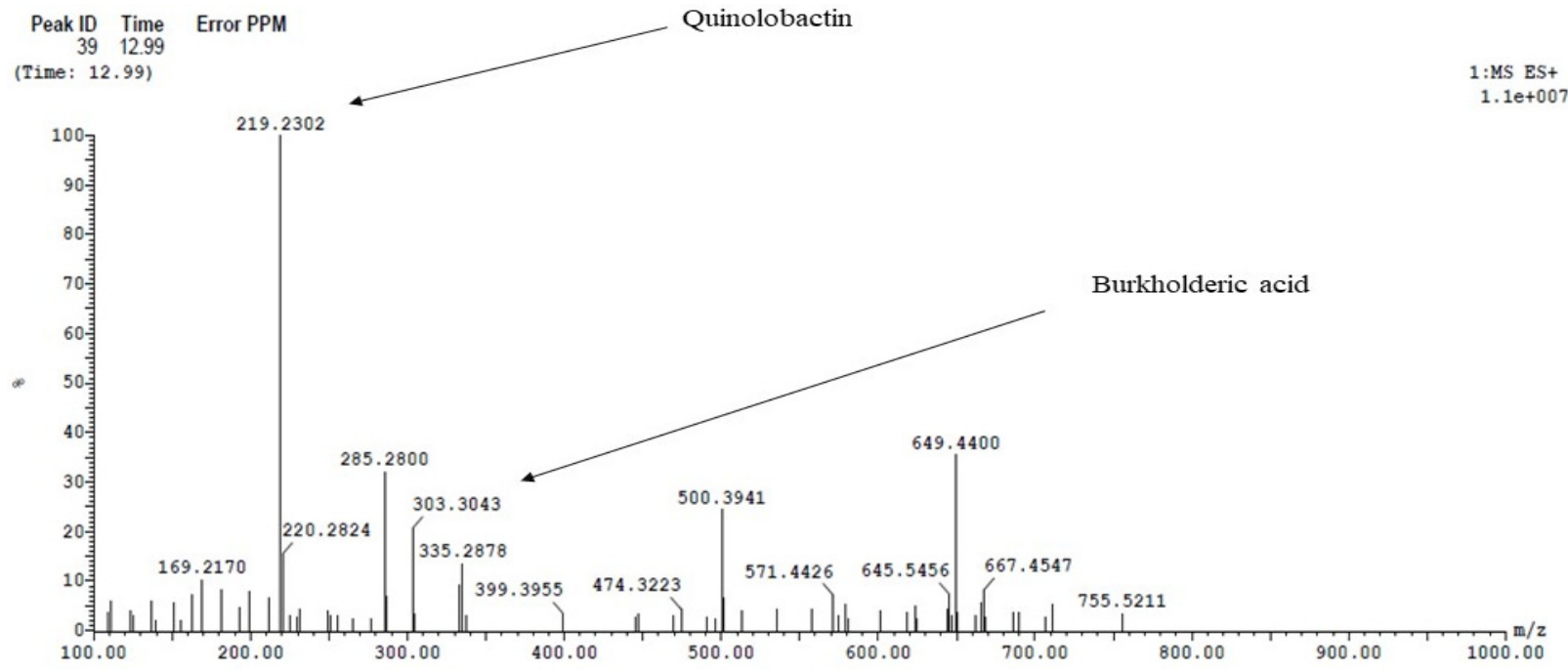

(c)

Figure 2. LC/MS analysis of a cell free ethyl acetate extract of A. faecalis isolate MZ921504 (a) detection of ectoine, (b) detection of bacillibactin, (c) detection of quinolobactin and Burkholderic acid. 


\subsection{Metagenomics Analysis of the Soil Sample}

We observed a range between 500-1080 reads in the sample and control. FastQ quality score per base showed good quality (Phred score range between 10 and $<25$ ). There were no duplicate reads. Sequence length (bp) ranged from 250-12,000 bp. Percentage N count (ambiguous) was zero.

Percent abundance of the bacterial phylum present in the soil, shows that the most abundant phylum was Achromobacter. The organism with the most abundance is Achromobacter sp. MFA1 R4 representing 56\% of the sample, followed by Achromobacter sp. AONIH1 and Achromobacter xylosoxidans, both of $11 \%$ abundance. A. faecalis belongs to Proteobacteria phylum which presented $0.4 \%$ abundance. There are two species related to Alcaligens genus present in the soil which are Alcaligens faecalis $(67 \%)$ and Alcaligens aquatilis (33\%) (Supplementary Material Figure S1). Metagenomics sequences were deposited in the NCBI GenBank under accession number PRJNA771993 (https: / / www.ncbi.nlm.nih.gov/sra/PRJNA771993, accessed on 7 November 2021).

\subsection{Identification of Secondary Metabolite(s) Gene Clusters}

The Figures 3-7 elaborates the similarity between the query genes in A. faecalis isolate MZ921504 against the database for the prediction of the produced metabolites, ectoine, bacteriocin, bacillibactin, $\beta$-lactones and terpenes, respectively. Genome similarity plays an important role in the synthesis of related compounds to pre-identified genes [20].

\subsubsection{Ectoine}

Ectoine is a protective substance for bacteria against osmotic pressure (Figure 3). The ectoine biosynthetic gene cluster of A. faecalis isolate MZ921504 (presented by the red color) showed homology to the top 13 ectoine gene clusters as depicted in Figure 3.

2.6.2. Bacteriocin or Other Unspecified Linear Ribosomal-Synthesized and Post-Translationally Modified Peptides (RiPP)

Bacteriocins are proteinaceous substance produced by bacteria to inhibit bacterial growth of other bacteria. The bacteriocin biosynthetic gene cluster sequence of $A$. faecalis isolate MZ921504 (query) has a 50\% similarity to homologous gene cluster producing methanobactin (Figure 4).

2.6.3. Hybrid Region: Resorcinol and Traditional (Multi-) Modular Non-Ribosomal Peptide Synthase (NRPS)

The gene cluster sequence of $A$. faecalis isolate MZ921504 has a $60 \%$ similarity to gene cluster of various Alcaligenes sp. producing Bacillibactin (Figure 5).

\subsubsection{Beta-Lactone Containing Protease Inhibitor}

$\beta$-lactones are natural products with potent antifungal and antibacterial activities [21]. The gene cluster sequence of $A$. faecalis isolate MZ921504 has a $26 \%$ similarity to gene clusters of various Alcaligenes producing quinolobactin as depicted in Figure 6.

\subsubsection{Terpene}

Terpene is a class of natural products consisting of compounds with the formula (C5H8)n. The gene cluster sequence of $A$. faecalis isolate MZ921504 (query sequence) has a $13 \%$ similarity to homologous gene clusters of various Alcaligenes producing Burkholderic acid (Figure 7). 


\section{- Gene Cluster 1}

Query sequence

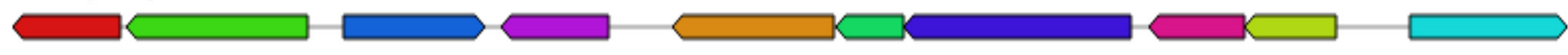

NZ_CP013119 (608222-618615): Alcaligenes faecalis strain ZD02, complete genome (100\% of genes show similarity), ectoi

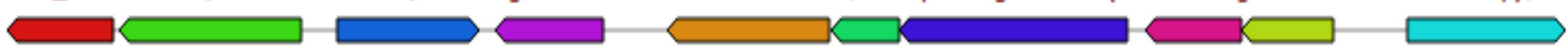

NZ_CP048039 (2908075-2918468): Alcaligenes faecalis strain MUB14 chromosome, ... (100\% of genes show similarity), ect $\longrightarrow \longrightarrow \longrightarrow \square$

NZ_CP032153 (2907384-2917777): Alcaligenes aquatilis strain QD168 chromosome,... (100\% of genes show similarity), ect $\longrightarrow \longrightarrow \longrightarrow \longrightarrow$

NZ_CP023667 (2369155-2379548): Alcaligenes faecalis strain DSM 30030 chromoso... (100\% of genes show similarity), ect $\longrightarrow \square \square \square$

NZ_CP021079 (2617092-2627485): Alcaligenes faecalis strain P156 chromosome, C... (100\% of genes show similarity), ecto $\longrightarrow \longrightarrow \square \longrightarrow \square \longrightarrow$

- $\quad$ Gene Cluster 2

Query sequence

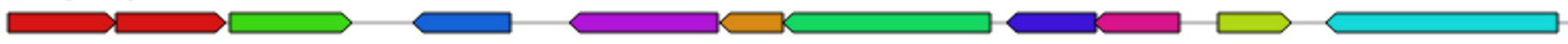

NZ_CP032521 (1231981-1242374): Alcaligenes faecalis strain J481 chromosome, c... (100\% of genes show similarity), ecto $\square \longrightarrow$

NZ_CP021641 (2728094-2738487): Alcaligenes faecalis strain JQ135 chromosome, ... (100\% of genes show similarity), ectc $\square \longrightarrow$

NZ_RHXD01000001 (137317-147710): Alcaligenes aquatilis strain 393 NODE 1 leng... (100\% of genes show similarity), ectc $\longrightarrow \square$

NZ_CP022390 (1642284-1652677): Alcaligenes aquatilis strain BU33N chromosome (100\% of genes show similarity), ectoin NZ_CP031012 (2723291-2733684): Alcaligenes faecalis strain Mc250 chromosome (100\% of genes show similarity), ectoine $\longrightarrow \longrightarrow$

NZ_KQ954457 (49150-59543): Alcaligenes faecalis strain NBIB-017 scaffold11, w... ( $90 \%$ of genes show similarity), ectoine $\longrightarrow$

NZ_CP031747 (48245-58638): Alcaligenes faecalis strain AU14 chromosome ( $90 \%$ of genes show similarity), ectoine

NZ CP036294 (526947-537340): Alcaligenes faecalis strain AN70 chromosome, com... (90\% of genes show similarity), ecto $\longrightarrow \square \longrightarrow$

Figure 3. Gene arrangement of top 13 ectoine gene clusters (presented in gene cluster 1 and 2 as compared to the query sequence of $A$. faecalis isolate MZ921504. The putative biosynthetic genes presented in red, additional biosynthetic genes in orange, transport-related genes in blue, regulation-related genes in green color, resistance genes in pink, TTA codon in dark pink.

Query sequence

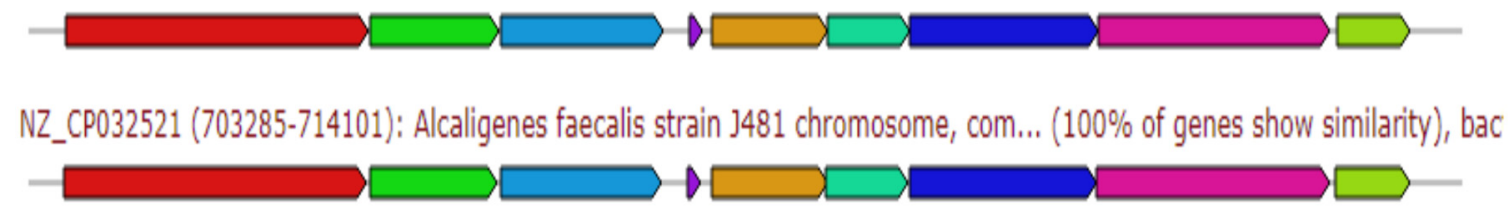

Figure 4. Gene arrangement of bacteriocin gene cluster homologous to query sequence of $A$. faecalis isolate MZ921504. Putative biosynthetic genes presented in red, additional biosynthetic genes in orange, transport-related genes in blue, regulation-related genes in green color, resistance genes in pink, TTA codon in dark pink. 
- $\quad$ Gene Cluster 1

Query sequence

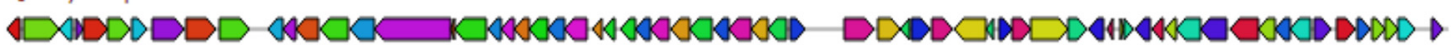

NZ_CP032521 (2785931-2861755): Alcaligenes faecalis strain J481 chromosome, C... (100\% of genes show similarity), NRP:

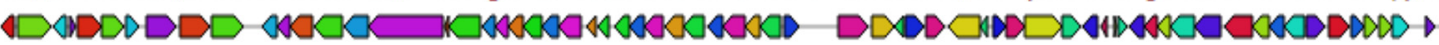

NZ_CP021641 (300146-375892): Alcaligenes faecalis strain JQ135 chromosome, co... ( $98 \%$ of genes show similarity), NRPS

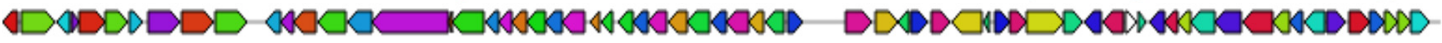

NZ_CP022390 (2895802-2971549): Alcaligenes aquatilis strain BU33N chromosome ( $97 \%$ of genes show similarity), NRPS, $\mathrm{r}$

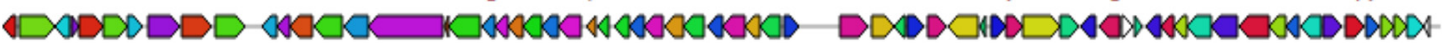

NZ_CP032153 (273247-348861): Alcaligenes aquatilis strain QD168 chromosome, C... ( $98 \%$ of genes show similarity), NRPs

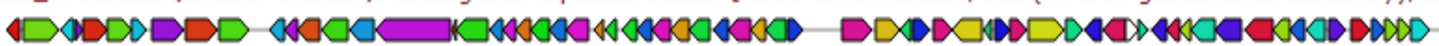

NZ_CP021883 (1972769-2049210): Alcaligenes faecalis strain BDB4 genome ( $94 \%$ of genes show similarity), NRPS, resorcin

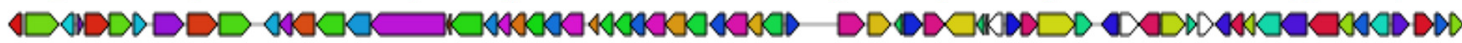

NZ_CP021079 (295201-371644): Alcaligenes faecalis strain P156 chromosome, com... (94\% of genes show similarity), NRPs

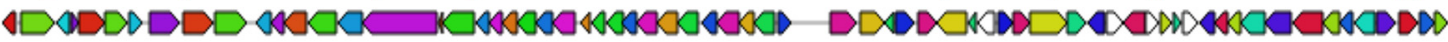

NZ_CP036294 (2161997-2237898): Alcaligenes faecalis strain AN70 chromosome, C... (96\% of genes show similarity), NRPC

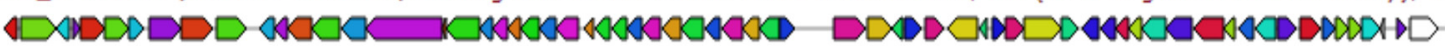

NZ_CP023667 (35093-111522): Alcaligenes faecalis strain DSM 30030 chromosome,... ( $95 \%$ of genes show similarity), NRP

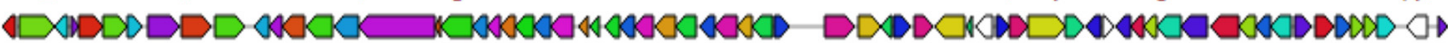

NZ_CP013119 (1974122-2050563): Alcaligenes faecalis strain ZD02, complete genome ( $92 \%$ of genes show similarity), NRF

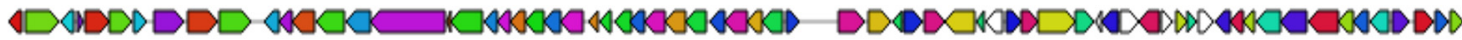

NZ_CP048039 (329222-405664): Alcaligenes faecalis strain MUB14 chromosome, co... (92\% of genes show similarity), NRPs

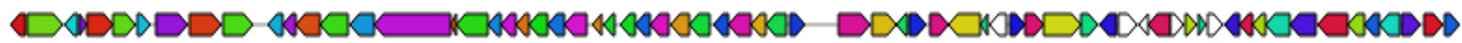

- $\quad$ Gene Cluster 2

Query sequence

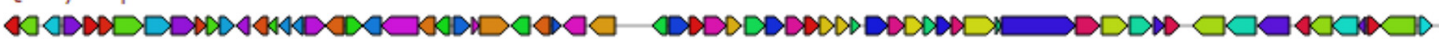

NZ_CP021079 (295201-371644): Alcaligenes faecalis strain P156 chromosome, com... (98\% of genes show similarity), NRPs

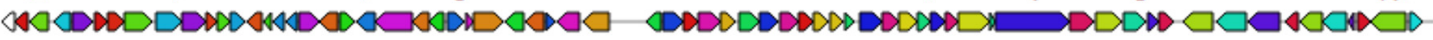

NZ_CP013119 (1974122-2050563): Alcaligenes faecalis strain ZD02, complete genome (97\% of genes show similarity), NRF

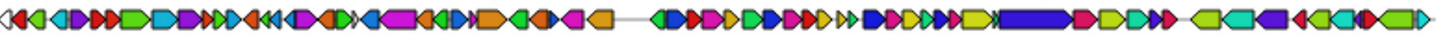

NZ_CP048039 (329222-405664): Alcaligenes faecalis strain MUB14 chromosome, co... (98\% of genes show similarity), NRPs

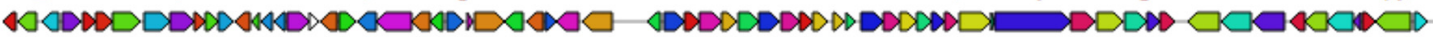

NZ_KQ954451 (13162-90035): Alcaligenes faecalis strain NBIB-017 scaffold5, wh... (98\% of genes show similarity), NRPS,r

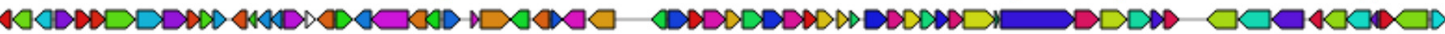

NZ_CP021883 (1972769-2049210): Alcaligenes faecalis strain BDB4 genome ( $97 \%$ of genes show similarity), NRPS,resorcin

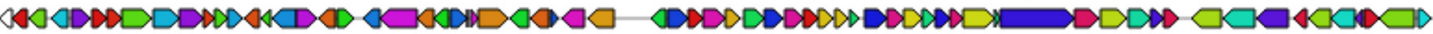

NZ_CP031012 (308896-385213): Alcaligenes faecalis strain Mc250 chromosome (95\% of genes show similarity), NRPS, resol

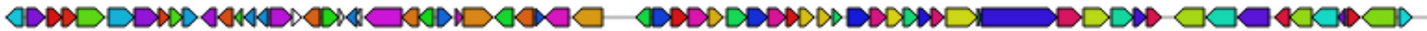

NZ_CP031747 (1982468-2058860): Alcaligenes faecalis strain AU14 chromosome (97\% of genes show similarity), NRPS,res

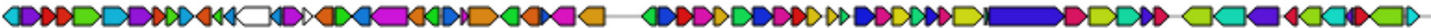

NZ_CP022390 (2895802-2971549): Alcaligenes aquatilis strain BU33N chromosome ( $94 \%$ of genes show similarity), NRPS, $\mathrm{r}$

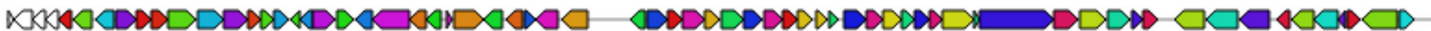

NZ_CP032153 (273247-348861): Alcaligenes aquatilis strain QD168 chromosome, c... (95\% of genes show similarity), NRPs

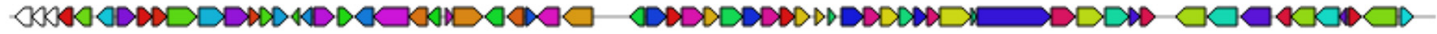

NZ_CP021641 (300146-375892): Alcaligenes faecalis strain JQ135 chromosome, co... (95\% of genes show similarity), NRPS

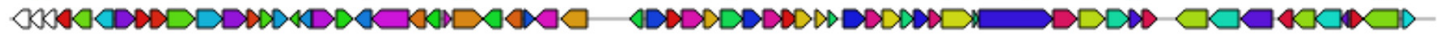

Figure 5. Gene arrangement of resorcinol and multi-modular non-ribosomal peptide synthase (NRPS) gene clusters of various Alcaligenes sp. homologous to query sequence of $A$. faecalis isolate MZ921504. Putative biosynthetic genes presented in red, additional biosynthetic genes in orange, transport-related genes in blue, regulation-related genes in green color, resistance genes in pink, TTA codon in dark pink. 
Query sequence

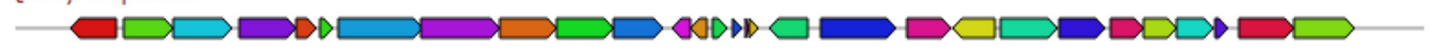

NZ_CP032521 (349213-376331): Alcaligenes faecalis strain 3481 chromosome, com... (100\% of genes show similarity), bet:

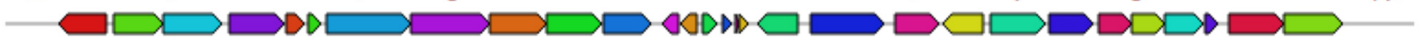

NZ_RHXD01000010 (53403-84104): Alcaligenes aquatilis strain 393 NODE 10 lengt... $100 \%$ EGK70 RS14850

NZ_RHXD01000010 (53403-84104): Alcaligenes aquatilis strain 393 NODE 10 lengt... (100\% of genes show similarity), beta

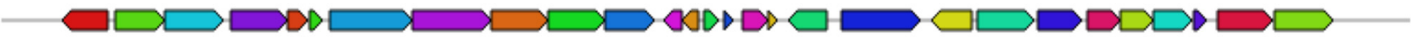

NZ_CP013119 (3851747-3882936): Alcaligenes faecalis strain ZD02, complete genome ( $90 \%$ of genes show similarity), betz

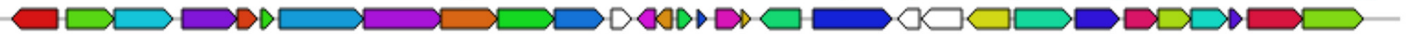

NZ_CP021883 (3850394-3881583): Alcaligenes faecalis strain BDB4 genome (87\% of genes show similarity), betalactone

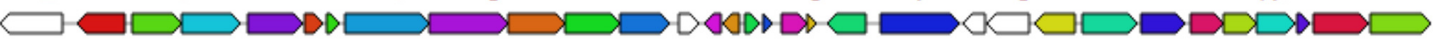

NZ_CP032153 (2056362-2087065): Alcaligenes aquatilis strain QD168 chromosome,... (93\% of genes show similarity), beta

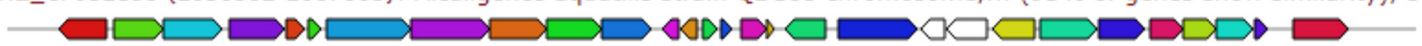

NZ_CP021079 (1734482-1765080): Alcaligenes faecalis strain P156 chromosome, C... (93\% of genes show similarity), betal:

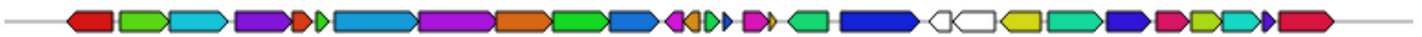

NZ_CP021641 (1746819-1776938): Alcaligenes faecalis strain JQ135 chromosome, ... (96\% of genes show similarity), betal

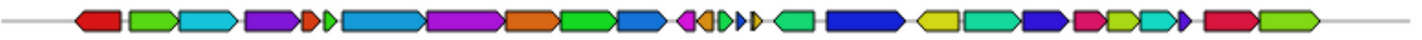

NZ_CP022390 (803393-833511): Alcaligenes aquatilis strain BU33N chromosome (100\% of genes show similarity), betalact

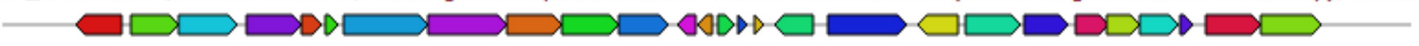

NZ_CP048039 (1997023-2028211): Alcaligenes faecalis strain MUB14 chromosome, ... (90\% of genes show similarity), beta

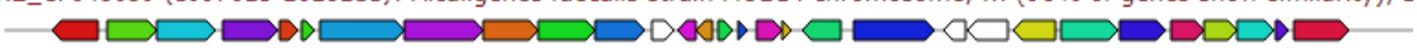

NZ_CP031012 (1821177-1852368): Alcaligenes faecalis strain Mc250 chromosome ( $90 \%$ of genes show similarity), betalact

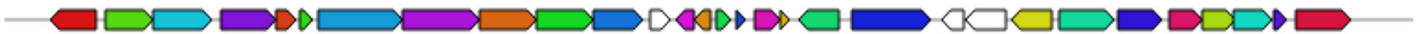

Figure 6. Gene arrangement of $\beta$-lactone containing protease inhibitors showing top 10 Alcaligenes faecalis strains homologous to query sequence of $A$. faecalis isolate MZ921504. Putative biosynthetic genes presented in red, additional biosynthetic genes in orange, transport-related genes in blue, regulation-related genes in green color, resistance genes in pink, TTA codon in dark pink.

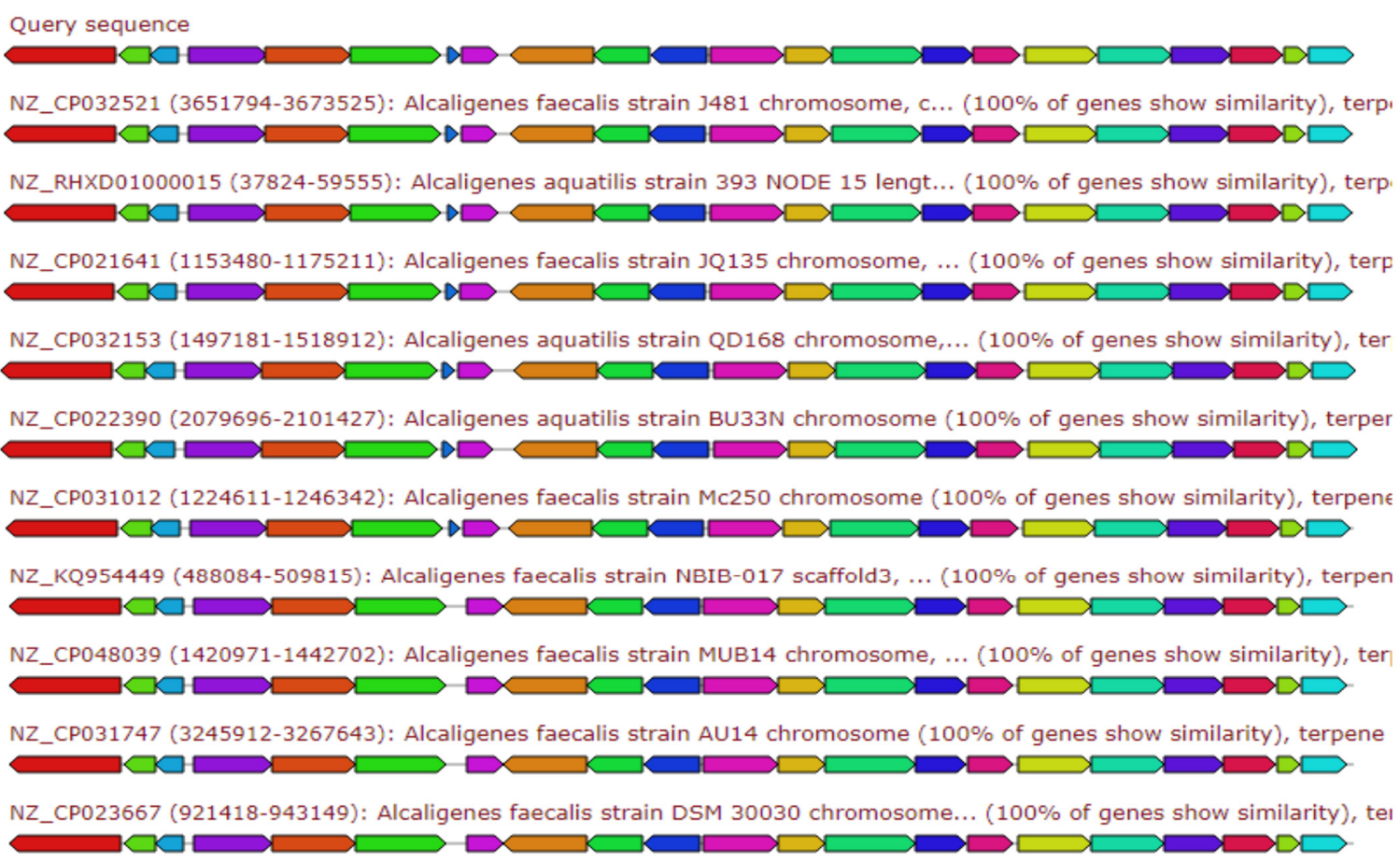

Figure 7. Gene arrangement of the top 10 Alcaligenes sp. showing homologous to query sequence of $A$. faecalis isolate MZ921504 for Terpene biosynthetic gene cluster. Putative biosynthetic genes presented in red, additional biosynthetic genes in orange, transport-related genes in blue, regulation-related genes in green color, resistance genes in pink, TTA codon in dark pink. 


\section{Discussion}

The development of new antimicrobial agents has become an urgent demand, as history dictates and proven that natural resources still provide humanity with solutions for development of several natural products including antimicrobials [22]. Soil significantly have been associated with several microorganisms that are antimicrobial producers and have been used extensively for antibiotic production, such as streptomycin from Streptomyces species [22]. A. faecalis has not always been associated with antimicrobial production, scarce studies on antimicrobial activity of $A$. faecalis have been published in the last few years [17-19]. In this study, it shows a promising approach for new antibiotic discovery as per secondary metabolite gene cluster results [17] and correlating these results with the antimicrobial and LC/MS spectroscopic analysis.

In the present study, preliminary screening was carried out on 15 different soil samples. Of these, one sample revealed the presence A. faecalis MZ921504 with broad antimicrobial activities against wide range of MDR gram positive and Gram-negative bacteria. This soil sample was selected for further metagenomics analysis of the secondary metabolite biosynthetic gene clusters. The isolated strain of $A$. faecalis from the soil exhibited a broad spectrum of antimicrobial activities. The crude ethyl acetate extract showed activity against colistin resistant $K$. pneumoniae, VRSA, MDR E. coli and little activity against $C$. albicans. Other studies showed different inhibitory spectrums. For instance, a strain of $A$. faecalis isolated from Passu glacier in Pakistan produced two antimicrobials which are kalimantacin and tunicamycin [23]. Both showed efficacy against large number of resistant pathogens, such as S. aureus, Bacillus subtilis, E. coli, K. pneumoniae and Pseudomonas aeruginosa [23]. In accordance to our study, Kapley et al., isolated A. faecalis HPC 1271 strain from a waste water treatment system called common effluent treatment plant (CETP) [17]. It showed promising inhibitory effects against MDR bacteria which were Serratia sp., Enterobacter sp. and reference organisms including, E. coli, Bacillus subtilis and Shigella flexneri, but showed no inhibition against Salmonella paratyphi and S. aureus [17]. Another strain isolated from Moroccan tannery waste assigned as A. faecalis BW1, its ethyl acetate extract showed antimycobacterial activity against Mycobacterium smegmatiss [19]. An isolated strain of $A$. faecalis from crude oil field in Malaysia showed inhibitory effect against Desulfovibrio sp., a sulfate reducing bacterium, using the isolate chloroform extract [24]. An antipseudomonal activity was exhibited by another strain called A. faecalis strain KEM24 isolated from Olabisi Onabanjo University Farmland [18]. The previous studies showed that A. faecalis is a promising bacterium as a source for production of antimicrobial compounds.

It was reported that the type of substrate used in the fermentation as a source of carbon, glucose and nitrogen etc. may influence the structure of produced secondary metabolites, such as antimicrobials [25,26]. In a study conducted by Kapley et al., the seed culture was carried out in M9 media [17] and then fermentation was completed in LuriaBertani (LB) broth at $37^{\circ} \mathrm{C}$, at $150 \mathrm{rpm}$ for $48 \mathrm{~h}$ producing antimicrobial [19]. Another study conducted on A. faecalis strain producing antimicrobial metabolites against Desulfovibrio sp., was cultivated in $1 \mathrm{~L}$ of marine broth under rotary agitation condition at $150 \mathrm{rpm}$ at $30^{\circ} \mathrm{C}$ for $96 \mathrm{~h}$ and metabolites were extracted by chloroform [24]. The different extraction solvents and procedures might have influenced secondary metabolite gene expression and the differences in antimicrobial spectrum. The previous conclusion is clear in our study, the medium used for the bacterial growth and fermentation was starch casein broth and extraction of secondary metabolites was carried out using ethyl acetate followed by dichloromethane.

In the current study the secondary metabolite was characterized using TLC and LC/MS. TLC was used as a preliminary method to determine the difference in Retention Factors (RF) and polarities of the metabolites. LC/MS was used to help identify the inhibitory compounds produced by A. faecalis. The LC/MS run reviewed vast diverse compounds found in the cell free extract of ethyl acetate. Correlation of the inhibitory compound was guided by the secondary metabolite gene clusters provided from sequencing and analyzing by antiSMASH. The correlation between the inhibitory compounds 
and secondary metabolite gene clusters was carried out by matching acquired mass peaks from LC/MS, with highest probability, with pre-identified compounds from secondary metabolite gene cluster analysis. The correlated metabolites in this study were ectoine, bacillibactin, quinolobactin and burkholderic acid. $\beta$-lactones such quinolobactin as are natural products that have been described to have potent antifungal and antibacterial activity on human cancer cell lines. Chemically, they are four-membered heterocycles with high ring-strain, electrophilicity and reactivity [21]. Methanobactin gene cluster was also found in gene annotation, but it was not correlated in LC/MS due to the limited detection limit of $\mathrm{m} / \mathrm{z}$ which was 1000 and methanobactin exact mass is $1170.26973 \mathrm{~g} / \mathrm{mol}$. Consistent with our study, Kapley et al., characterized of the antimicrobial compound of A. faecalis HPC 1271 was carried out by solvent extraction using ethyl acetate followed by metabolite profiling using HPLC and LC-MS [17]. On the other hand, the A. faecalis from crude oil field in Malaysia chloroform extract was analyzed using Gas Chromatography Mass Spectrometry (GC-MS). The GC-MS analysis from Malaysian study revealed that the extract contains several antimicrobials, such as decanedioic acid, hexacosane, phenol, 7-hexadecene, 9-eicosene, palmitoleic acid [24].

Metagenomics is known to be a prominent approach for antimicrobial discovery from natural sources [10]. In the current study metagenomics gave an insight of the soil composition collected from Luxor aiming for antibiotic discovery. Although, the most abundant organism is Achromobacter sp. MFA1 R4 representing 56\%, the organism with the most promising inhibitory effect was A. faecalis belonging to the Proteobacteria phylum. Similar to our study, metagenomics analysis of a soil sample in Mars Oasis in the southern maritime Antarctic reported the availability of biosynthetic gene cluster (BGC) in metagenomes [27]. BCGs were found several phyla, such as Verrucomicrobiota, Acidobacteriota and Gemmatimonadota as well as classes of Actinobacteria represented in gammaproteobacterial, Thermoleophilia and Acidimicrobiia [27]. A deep sequencing of Mantag Mangrove forests soil in Malaysia (two different locations) using Illumina HiSeq 2500 platform that the most revealed that the

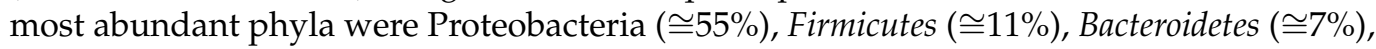
Chloroflexi, Planctomycetes, Actinobacteria and Cyanobacteria ( $\cong 3-5 \%$ each) [28]. Different metagenomics studies represent the different microbial communities with an open realm of opportunities for antimicrobial discovery.

Genome sequencing for secondary metabolite gene clusters was performed on the selected isolate. AntiSMASH analysis showed five gene clusters responsible for production of secondary metabolites. Gene sequencing followed by gene clusters analysis and correlation with LC/MS is a promising technique to guide for the identification of antimicrobial metabolites. The genetic analysis also provided us with information that the isolate produces several metabolites which might be the reason they exhibited a broad spectrum of activity against MDR bacteria and colistin resistant bacteria and VRSA. Gene cluster analysis suggested that $A$. faecalis produces bacteriocins similar compounds with high probability of methanobactin. Another gene cluster is $\beta$-lactone containing protease inhibitor with some genetic similarity of qinolobactins where this family of compounds are affiliated with activity against bacteria, fungi, or human cancer cell lines [29]. A 60\% gene similarity of bacillibactin is detected within one hybrid region: Resorcinol and traditional (multi-)modular non-ribosomal peptide synthases (NRPS). Bacillibactin is usually produced from Bacillus spp. which is an iron regulatory siderophore and exhibits antimicrobial activity [30,31]. A gene cluster also responsible for production of terpenes was found. Several terpene compounds exhibited antimicrobial activity [32,33]. The genetic annotation and assembly conducted in the study by Kapley et al., has several similarities with the current study. Consistent with our study, the genome assembly revealed secondary metabolite gene clusters of ectoine, terpene and NRPS [17]. It also had diverse secondary metabolite gene cluster butyrolactone, phosphonate and type 1 polyketide synthase (T1PKS) [17]. The production of a highly reduced metabolites, such as macrolide antibiotic is correlated with the type 1 modular NRPS which is naturally found in several types of bacteria and fungi as well as symbionts of higher eukaryotes [34,35]. 
The different inhibitory spectrum might be attributed to several factors apart from the difference in genomic data. The growth conditions that were subjected upon the different isolates might be a contributor to the produced metabolite, that can be the different incubation temperatures and the culture mediums used for the isolate growth [26]. Extraction and analysis methods also contributes to the diversified results in this approach [36]. The microbial community that the bacteria isolated from differs greatly from one environment to another which can influence in gene regulation and expression $[27,28]$.

It is recommended in future work to apply further analytical processing of the extract to completely isolate and identify the antimicrobial metabolites by applying fermentation on a larger scale, to produce sufficient amounts of the metabolites, followed by further purification and fractionation methods.

\section{Materials and Methods}

\subsection{Isolation and Characterization}

The soil samples were collected from different localities in Egypt and were air dried for one week before any further analysis to decrease the microbial count [37]. A suspension of $1 \mathrm{~g}$ of each soil sample in $9 \mathrm{~mL}$ saline was prepared [38] and was vortexed at $400 \mathrm{rpm}$ for 4 min. [39]. A series of 10-fold serial dilutions were performed from 10-1 to 10-6. For every dilution, about $1 \mathrm{~mL}$ was transferred for a surface inoculation on Starch Casein Agar (SCA) [37]. After an incubation period of 7 days, preliminary screening was performed on various bacterial isolates to determine its inhibitory effect against the tested organisms. Microscopical analysis and variable biochemical tests were performed for the preliminary identification of the recovered bacterial isolates $[40,41]$.

\subsection{Preliminary Screening}

In this case, 17 bacterial isolates were recovered from the 15 different soil samples and were screened for the antimicrobial activities against standard E. coli ATCC 25922 and three Staphylococcus (S.) epidermidis (SE1, SE2, SE3), three vancomycin resistance S. aureus (VRSA1, VRSA2, VSRA3), three multidrug resistant (MDR) K. pneumoniae (KP1, KP2, KP3), two MDR E. coli (EC1, EC2), three Candida (C.) albicans (CA1, CA2, CA3), and three C. auris (CS1, CS2, CS3) clinical isolates discharged from the Central Microbiology Lab of Ain Shams Hospital. The antimicrobial resistance patterns of the respective clinical isolates are displayed in Table 4. The 17 isolates were inoculated on Mueller Hinton agar (MHA) and the test organisms were inoculated perpendicularly to the isolate $[42,43]$. The plates were then incubated for $24 \mathrm{~h}$. at $37^{\circ} \mathrm{C}$. The antimicrobial activities were detected by the observing the inhibition zone around the tested organisms [42,44].

Table 4. Antimicrobial resistance profile of the bacterial clinical isolates.

\begin{tabular}{cccc}
\hline \multicolumn{2}{c}{ Gram Positive } & & Gram Negative \\
\hline Clinical Isolate Code & Resistance Pattern & Clinical Isolate Code & Resistance Pattern \\
\hline \multirow{2}{*}{ SE1, SE2, SE3 } & CLI, CN, FOX, CIP & KP1 & AMC, ATM, CTX, CAZ, CRO, FEP, CIP, SXT, \\
& & & TET, IMP, ETP, DOR, CT, PB, FF, RA, CN \\
VRSA1 & VAN, FOX & KP2 & AK, AMC, ATM, CTX, CAZ, CRO, FEP, CIP, \\
& & SXT, TET, IMP, ETP, DOR, CT, FF, RA, CN \\
VRSA2, VSRA3 & VAN, CLI, CN, FOX, CIP & AK, AMC, ATM, CTX, CAZ, CRO, FEP, CIP, \\
& & EX1 & SXT, TET, IMP, ETP, DOR, FF, RA, CN \\
& & EC2 & AK, AMC, ATM, CTX, CAZ, CRO, FEP, CIP, \\
& & SXT, TET, IMP, ETP, DOR, FF, RA, \\
\hline
\end{tabular}

Glycopeptides: VAN = vancomycin, Macrolides: CLI = clindamycin Beta-lactams: AMC = Amoxicillin/clavulanic ATM = Aztreonam FOX = cefoxitin CTX = Cefotaxime CAZ = Ceftazidime CRO = Ceftriaxone FEP = Cefepime DOR = Doripenem ETP = Ertapenem IMP = Imipenem; Aminoglycoside: $\mathrm{AK}=$ Amikacin $\mathrm{CN}=$ Gentamicin Quinolones: $\mathrm{CIP}=$ Ciprofloxacin Polymyxins: $\mathrm{CT}=\mathrm{Colistin}$ $\mathrm{PB}=$ Polymyxin B; Sulfonamides/Diaminopyrimidine: SXT = Sulfamethoxazole/Trimethoprim Tetracyclines: TE = Tetracycline; TGC = Tigecycline Phosphonic acid derivative: FF = Fosfomycin Rifamycins: RA = Rifamycin . 


\subsection{DNA Sequencing of $16 S$ Ribosomal RNA}

The $16 \mathrm{~S}$ ribosomal RNA of the isolate that showed promising and broad antimicrobial activity in the preliminary screening was sequenced and analyzed by GATC Biotech Co., Germany through Sigma Scientific Services Co., Egypt. The provided contig of the 16s ribosomal RNA was aligned and blasted in GenBank database using Basic Local Alignment Search Tool (BLAST, https:/ /blast.ncbi.nlm.nih.gov/Blast.cgi, accessed on 7 November 2021) provided by National Center of Biotechnology Information (NCBI). The results were then expressed as percentage homology between the query sequence and the sequences provided by the database. The alignment of the $16 \mathrm{~S}$ ribosomal RNA sequence against the sequence from the database was carried out using Multiple Sequence Comparison by Log- Expectation (MUSCLE, https://www.ebi.ac.uk/Tools/msa/muscle/, accessed on 7 November 2021) to retrieve phylogenetic tree. Phylogenetic tree was inferred via likelihood method with a bootstrap analysis (1000 replicates). The $16 \mathrm{~S}$ ribosomal RNA sequence was deposited in the NCBI GenBank.

\subsection{Production of the Antimicrobial Metabolite(s) in Shake Flasks Seed Culture Preparation and Production Conditions}

The seed culture was prepared by transferring a loopful of fresh culture of the promising bacterial isolate(s) into $50 \mathrm{~mL}$ starch casein broth and was incubated at $200 \mathrm{rpm}$ at $35^{\circ} \mathrm{C}$ for $24 \mathrm{~h}$. About one $\mathrm{ml}$ of the culture was centrifuged for $5 \mathrm{~min}$ at $16,000 \mathrm{rpm}$ using a micro centrifuge tube, washed twice with $1 \mathrm{~mL}$ sterile saline, and used to inoculate the production flasks ( $100 \mathrm{~mL}$ of casein starch broth $\times 20$ flasks). These flasks were incubated in a shaking incubator $(150 \mathrm{rpm})$ at $35^{\circ} \mathrm{C}$ for $7-10$ days [45]. The separation of the biomass was carried out by centrifugation at 10,000 rpm for $10 \mathrm{~min}$. The filtrate was then passed through $0.45 \mu \mathrm{m}$ membrane filter (Merck, Darmstadt, Germany) separate bacterial cells from the culture medium.

\subsection{Purification of the Antimicrobial Metabolite(s) \\ Extraction of the Antimicrobial Metabolite(s)}

Extraction was carried out sequentially using solvent extraction method. The solvents used were ethyl acetate and dichloromethane. Ethyl acetate was added first to the filtrate in equal volumes in a separating funnel [45]. The mixture was agitated for $2 \mathrm{~h}$ at $10 \mathrm{~min}$ intervals and left-over night for complete separation. The upper organic layer was collected and stored $4{ }^{\circ} \mathrm{C}$ for further analysis. The previous steps were repeated for dichloromethane [45]. The organic layers from ethyl acetate and dichloromethane were dried using rotary evaporator (Buchi R205, Flawil, Switzerland) at $45^{\circ} \mathrm{C}[44,46,47]$. Extracts were examined for its antimicrobial activities using agar well diffusion technique and negative controls were prepared using dimethyl sulfoxide (DMSO).

\subsection{In Vitro Testing of the Antimicrobial Activities of the Extracted Metabolite(s)}

The crude extract from ethyl acetate and dichloromethane were both dissolved in DMSO [42]. The antimicrobial testing was performed using both extracts and the filtrate left after extraction with both solvents using well diffusion method [44]. The two organic extracts were tested against eight organisms (S. aureus ATCC 25293, VRSA2, KP1, KP2, EC1, EC2, C. albicans ATCC 10231, CA1). A negative a control well was filled with DMSO [44].

\subsection{Characterization of the Antimicrobial Metabolite(s)}

\subsubsection{Thin Layer Chromatography (TLC) Analysis}

Preliminary separation of the metabolite(s) was carried out to the ethyl acetate extract using TLC analysis. The crude ethyl acetate extract was spotted on Silica TLC coated plates $20 \times 20 \mathrm{~cm}$ (pre-coated with silica gel 60 F254, Merck, Germany) and developed in three different solvent systems. The three solvent systems were: ethyl acetate: methanol (9:1); Ethyl acetate: dichloromethane (9:1); and dichloromethane: methanol (6.5:3.5). The 
fractionated metabolites were observed under UV light at $365 \mathrm{~nm}$ (fluorescence) and $254 \mathrm{~nm}$ (absorbance) [48].

\subsubsection{Liquid Chromatography-Mass Spectroscopy (LC/MS) Analysis}

LC/MS analysis was performed at Center for Drug Discovery Research and Development at Faculty of Pharmacy, Ain Shams University, Cairo, Egypt. The analysis was performed using ESI-MS positive and negative ion acquisition mode with a XEVO TQD triple quadruple instrument, Waters Corporation, Milford, MA01757 USA, mass spectrometer. The stationary phase was a ACQUITY UPLC—BEH C18 $1.7 \mu \mathrm{m}-2.1 \mathrm{~mm} \times 50 \mathrm{~mm}$ Column (Santa Clara, CA USA). The mobile phase was gradient elution consisted of water containing $0.1 \%$ formic acid and acetonitrile containing $0.1 \%$ formic acid with flow rate of $0.2 \mathrm{~mL} / \mathrm{min}$.

\subsection{Metagenomics Analysis of the Soil Samples}

\subsubsection{DNA Extraction and Quantification}

Metagenomics were carried out by HITS Solutions Co. (Bioinformatics Department, Cairo, Egypt, http:/ /www.hitssolutions.com/, accessed on 7 November 2021). Qiagen DNeasy power-soil kit (Cat. no. 12888-50 Qiagen, Germany) was used for DNA extraction as per manufacturer protocol. After DNA extraction the DNA quantity was measured by Qubit fluorometer ver. 4.0 to ensure there is enough pure genomic material before the sequencing run. $400 \mathrm{ng} / 7 \mu \mathrm{L}(55 \mathrm{ng} / \mu \mathrm{L})$, as mentioned by Oxford nanopore manual.

\subsubsection{Library Construction}

Library construction was performed using Rapid Sequencing Kit (Oxford Nanopore Technologies, Oxford, UK, Cat. \# SQK-RAD004). Before loading on the flow cell, a total of $34 \mu \mathrm{L}$ of sequencing Buffer and $25.5 \mu \mathrm{L}$ of loading Beads were added to $12 \mu \mathrm{L}$ of the DNA libraries and $4.5 \mu \mathrm{L}$ nuclease free water. After that priming and loading onto FLO-MIN106 flow cell were performed.

\subsubsection{Sequencing and Data Analysis}

Sequencing was run on MinION ${ }^{\mathrm{TM}}$ (Oxford Nanopore Technologies, Oxford, UK) for $12 \mathrm{~h}$ which generates $3.03 \mathrm{M}$ reads with N50 equals $9.29 \mathrm{~K}$. Base calling was performed in real-time during sequencing by the Guppy software. which generates FAST5 and FASTq files, reads below Q7 were eliminated. Centrifuge was used to classify sequencing reads to a taxonomic identifier. A Centrifuge index was constructed using bacterial and viral genomes downloaded from NCBI RefSeq as of 03 March2017, and the human reference genome (GRCh38). Low complexity regions with a dust score greater than 20 in the reference sequences were masked using dust masker (v 1.0.0, NCBI). Results were visualized using re-centrifuged.

\subsubsection{Genome Sequencing Aligning and Analysis}

From the previous step of soil sequencing analysis of the metagenome using antiSMASH version 2 (Antibiotics and Secondary Metabolite Analysis Shell) (http:/ / antismash. secondarymetabolites.org/, accessed on 7 November 2021) for extraction probable secondary metabolite gene cluster of the isolate. Mauve software was used (http:/ / gel.ahabs. wisc.edu/mauve, accessed on 7 November 2021) for draft genome comparison [17].

\section{Conclusions}

A. faecalis isolate MZ921504 is a promising source for antimicrobial metabolites with broad activities against MDR Gram positive and Gram-negative bacteria. The LC/MS analysis of A. faecalis metabolites confirmed the presence of ectoine, bacillibactin, quinolobactin and burkholderic acid. Metagenomics sequence analysis of the soil sample containing the respective isolate revealed the presence of conserved biosynthetic gene clusters of ectoine, bacteriocin, bacillibactin, quinolobactin, terpene and burkholderic acid. The obtained data 
confirmed the suitability of the metagenomic nanopore sequence analysis, which is a fast and reliable method for deciphering the nature of the active metabolites and potential is exhibited through cutting off the huge amount of time that was required for random antimicrobial discovery from natural sources.

Supplementary Materials: The following are available online at https://www.mdpi.com/article/ 10.3390/antibiotics10111382/s1, Figure S1: Metagenomics analysis of soil showing the diversity of Alcaligens species.

Author Contributions: Conceptualization, M.A.E., W.N.E., B.T.S., M.R.E.-A., K.M.A. and M.S.E.A.; methodology, M.A.E., W.N.E., K.M.A. and M.S.E.A.; formal analysis, M.A.E.; writing—original draft preparation, M.A.E. and W.N.E.; writing-review and editing, M.A.E., W.N.E., M.R.E.-A. and K.M.A.; supervision, M.A.E., W.N.E. and M.S.E.A.; funding acquisition, M.A.E., W.N.E., B.T.S. and M.R.E.-A. All authors have read and agreed to the published version of the manuscript.

Funding: This research received no external funding.

Data Availability Statement: Data are available within the article.

Conflicts of Interest: The authors declare no conflict of interest.

\section{References}

1. Freire-Moran, L.; Aronsson, B.; Manz, C.; Gyssens, I.C.; So, A.D.; Monnet, D.L.; Cars, O.; ECDC-EMA Working Group. Critical shortage of new antibiotics in development against multidrug-resistant bacteria-Time to react is now. Drug Resist. Updat. 2011, 14, 118-124. [CrossRef]

2. Rex, J.H.; Talbot, G.H.; Goldberger, M.J.; Eisenstein, B.I.; Echols, R.M.; Tomayko, J.F.; Dudley, M.N.; Dane, A.D. Progress in the fight against multidrug-resistant bacteria 2005-2016: Modern noninferiority trial designs enable antibiotic development in advance of epidemic bacterial resistance. Clin. Infect. Dis. 2017, 65, 141-146. [CrossRef]

3. Spellberg, B.; Guidos, R.; Gilbert, D.; Bradley, J.; Boucher, H.W.; Scheld, W.M.; Bartlett, J.G.; Edwards, J., Jr.; Infectious Diseases Society of America. The epidemic of antibiotic-resistant infections: A call to action for the medical community from the Infectious Diseases Society of America. Clin. Infect. Dis. 2008, 46, 155-164. [CrossRef]

4. Chouchani, C.; Rolain, J.-M.; Ghrairi, T. Recent advances in antimicrobial and bacterial resistance. Int. J. Antimicrob. Agents. 2018, 52, 869-870. [CrossRef]

5. Khameneh, B.; Diab, R.; Ghazvini, K.; Bazzaz, B.S.F. Breakthroughs in bacterial resistance mechanisms and the potential ways to combat them. Microb. Pathog. 2016, 95, 32-42. [CrossRef]

6. Katz, L.; Baltz, R.H.J. Natural product discovery: Past, present, and future. J. Ind. Microbiol. Biotechnol. 2016, 43, 155-176. [CrossRef] [PubMed]

7. Chandra, N.; Kumar, S. Antibiotics producing soil microorganisms. In Antibiotics and Antibiotics Resistance Genes in Soils; Springer: Berlin/Heidelberg, Germany, 2017; pp. 1-18.

8. Delgado-Baquerizo, M.; Oliverio, A.M.; Brewer, T.E.; Benavent-González, A.; Eldridge, D.J.; Bardgett, R.D.; Maestre, F.T.; Singh, B.K.; Fierer, N. A global atlas of the dominant bacteria found in soil. Science 2018, 359, 320-325. [CrossRef] [PubMed]

9. Land, M.; Hauser, L.; Jun, S.-R.; Nookaew, I.; Leuze, M.R.; Ahn, T.-H.; Karpinets, T.; Lund, O.; Kora, G.; Wassenaar, T.; et al. Insights from 20 years of bacterial genome sequencing. Funct. Integr. Genomics 2015, 15, 141-161. [CrossRef] [PubMed]

10. Hover, B.M.; Kim, S.-H.; Katz, M.; Charlop-Powers, Z.; Owen, J.G.; Ternei, M.A.; Maniko, J.; Estrela, A.B.; Molina, H.; Park, S. Culture-independent discovery of the malacidins as calcium-dependent antibiotics with activity against multidrug-resistant Gram-positive pathogens. Nat. Microbiol. 2018, 3, 415-422. [CrossRef] [PubMed]

11. Jayanth, K.; Jeyasekaran, G.; Shakila, R.J. Isolation of marine bacteria, antagonistic to human pathogens. Indian J. Mar. Sci. 2002, $31,39-44$.

12. Bernan, V.; Greenstein, M.; Maiese, W.M. Marine microorganisms as a source of new natural products. Adv. Appl. Microbiol. 1997, 43, 57-90.

13. Gauthier, M.; Shewan, J.; Gibson, D.; Lee, J.V. Taxonomic position and seasonal variations in marine neritic environment of some gram-negative antibiotic-producing bacteria. J. Gen. Microbiol. 1975, 87, 211-218. [CrossRef]

14. Abdelgalil, S.A.; Attia, A.R.; Reyed, R.M.; Soliman, N.A. Partial purification and biochemical characterization of a new highly acidic NYSO laccase from Alcaligenes faecalis. J. Genet. Eng. Biotechnol. 2020, 18, 79. [CrossRef]

15. Maré, I.J.; Coetzee, J.N. Antibiotics of Alcaligenes faecalis. Nature 1964, 203, 430-431. [CrossRef]

16. Zahir, I.; Houari, A.; Bahafid, W.; Iraqui, M.; Ibnsouda, S. A novel Alcaligenes faecalis antibacterial-producing strain isolated from a Moroccan tannery waste. Afr. J. Microbiol. Res. 2013, 7, 5314-5323.

17. Kapley, A.; Tanksale, H.; Sagarkar, S.; Prasad, A.; Kumar, R.A.; Sharma, N.; Qureshi, A.; Purohit, H.J. Antimicrobial activity of Alcaligenes sp. HPC 1271 against multidrug resistant bacteria. Funct. Integr. Genom. 2016, 16, 57-65. [CrossRef] [PubMed] 
18. Onajobi, I.B.; Idowu, E.O.; Adeyemi, J.O.; Samson, O.J.; Ogunyinka, P.I.; Fagade, O.E. In vitro antibacterial activities and molecular characterization of bacterial species isolated from farmlands against selected pathogens. Biotechnol. Rep. (Amst.) 2020, $27, \mathrm{e} 00513$. [CrossRef] [PubMed]

19. Zahir, I.; Houari, A.; Iraqui, M.; Ibnsouda, S. Partial purification and antimycobacterial screening of the ethyl acetate extract of Alcaligenes faecalis BW1. Br. Microbiol. Res. J. 2014, 4, 1178-1188. [CrossRef]

20. Arulprakasam, K.R.; Dharumadurai, D. Genome mining of biosynthetic gene clusters intended for secondary metabolites conservation in actinobacteria. Microb. Pathog. 2021, 161, 105252. [CrossRef] [PubMed]

21. Robinson, S.L.; Wackett, L.P. Rings of Power: Enzymatic Routes to $\beta$-Lactones. In Comprehensive Natural Products III, 3rd ed.; Elsevier: Amsterdam, The Netherlands, 2020; Volume 4, pp. 323-345.

22. Hutchings, M.I.; Truman, A.W.; Wilkinson, B. Antibiotics: Past, present and future. Curr. Opin. Microbiol. 2019, 51, 72-80. [CrossRef]

23. Rafiq, M.; Hayat, M.; Hassan, N.; Ibrar, M.; Haleem, A.; Rehman, M.; Ahmad, F.; Shah, A.A.; Hasan, F. Characterization of antibacterial compounds produced by psychrotrophic Alcaligenes faecalis HTP6 isolated from Passu Glacier, Pakistan. Int. J. Biosci. 2016, 8, 122-135.

24. Abd Sharad, A.; Usupb, G.; Sahrani, F.K.; Ahmad, A. Bioactivity of Natural Compounds Produced by Marine Alcaligenes faecalis as Antimicrobial, Antibiofilm Formation and Anti-biocorrosion Effect against Desulfovibrio sp. Isolated from Crude Oil Fluid. 2018. Available online: https://www.researchgate.net/publication/329130286_Bioactivity_of_natural_compounds_Produced_by_ Marine_Alcaligenes_faecalis_as_Antimicrobial_antibiofilm_formation_and_anti-biocorrosion_effect_against_Desulfovibrio_ sp_Isolated_from_crude_oil_fluid (accessed on 10 November 2021).

25. Fiddaman, P.; Rossall, S. Effect of substrate on the production of antifungal volatiles from Bacillus subtilis. J. Appl. Bacteriol. 1994, 76, 395-405. [CrossRef]

26. Abouseoud, M.; Maachi, R.; Amrane, A.; Boudergua, S.; Nabi, A. Evaluation of different carbon and nitrogen sources in production of biosurfactant by Pseudomonas fluorescens. Desalination 2008, 223, 143-151. [CrossRef]

27. Waschulin, V.; Borsetto, C.; James, R.; Newsham, K.K.; Donadio, S.; Corre, C.; Wellington, E. Biosynthetic potential of uncultured Antarctic soil bacteria revealed through long-read metagenomic sequencing. ISME J. 2021. [CrossRef]

28. Priya, G.; Lau, N.-S.; Furusawa, G.; Dinesh, B.; Foong, S.Y.; Amirul, A.-A.A. Metagenomic insights into the phylogenetic and functional profiles of soil microbiome from a managed mangrove in Malaysia. Agric. Gene 2018, 9, 5-15. [CrossRef]

29. Heeb, S.; Fletcher, M.P.; Chhabra, S.R.; Diggle, S.P.; Williams, P.; Cámara, M. Quinolones: From antibiotics to autoinducers. FEMS Microbiol. Rev. 2011, 35, 247-274. [CrossRef] [PubMed]

30. Nithyapriya, S.; Lalitha, S.; Sayyed, R.; Reddy, M.; Dailin, D.J.; El Enshasy, H.A.; Luh Suriani, N.; Herlambang, S. Production, Purification, and Characterization of Bacillibactin Siderophore of Bacillus subtilis and Its Application for Improvement in Plant Growth and Oil Content in Sesame. Sustainability 2021, 13, 5394. [CrossRef]

31. Su, Z.; Chen, X.; Liu, X.; Guo, Q.; Li, S.; Lu, X.; Zhang, X.; Wang, P.; Dong, L.; Zhao, W.; et al. Genome mining and UHPLC-QTOFMS/MS to identify the potential antimicrobial compounds and determine the specificity of biosynthetic gene clusters in Bacillus subtilis NCD-2. BMC Genom. 2020, 21, 1-16. [CrossRef] [PubMed]

32. Gallucci, M.N.; Oliva, M.; Casero, C.; Dambolena, J.; Luna, A.; Zygadlo, J.; Demo, M. Antimicrobial combined action of terpenes against the food-borne microorganisms Escherichia coli, Staphylococcus aureus and Bacillus cereus. Flavour Frag. J. 2009, 24, 348-354. [CrossRef]

33. Mahizan, N.A.; Yang, S.-K.; Moo, C.-L.; Song, A.A.-L.; Chong, C.-M.; Chong, C.-W.; Abushelaibi, A.; Lim, S.-H.E.; Lai, K.-S. Terpene derivatives as a potential agent against antimicrobial resistance (AMR) pathogens. Molecules 2019, 24, 2631. [CrossRef]

34. Soltani, J. Chapter 22-Secondary Metabolite Diversity of the Genus Aspergillus: Recent Advances. In New and Future Developments in Microbial Biotechnology and Bioengineering; Elsevier: Amsterdam, The Netherlands, 2016; pp. 275-292.

35. Zheng, J.; Keatinge-Clay, A.T. The status of type I polyketide synthase ketoreductases. Med. Chem. Commun. 2013, 4, 34-40. [CrossRef]

36. Jeyaseelan, E.C.; Pathmanathan, M.K.; Jeyadevan, J.P. Inhibitory effect of different solvent extracts of Vitex negundo L. and Allium sativum L. on phytopathogenic bacteria. Arch. Appl. Sci. Res. 2011, 3, 1-8.

37. Jeffrey, L.J.S. Isolation, characterization and identification of actinomycetes from agriculture soils at Semongok, Sarawak. Afr. J. Biotechnol. 2008, 7, 3697-3702.

38. Yilmaz, E.I.; Yavuz, M.; Kizil, M. Molecular characterization of rhizospheric soil streptomycetes isolated from indigenous Turkish plants and their antimicrobial activity. World J. Microbiol. Biotechnol. 2008, 24, 1461-1470. [CrossRef]

39. Agadagba, S.K. Isolation of Actinomycetes from soil. J. Microbiol. Biotechnol. 2014, 4, 136-140.

40. Elston, H.R.; Baudo, J.A.; Stanek, J.P.; Schaab, M. Multi-biochemical test system for distinguishing enteric and other gram-negative bacilli. Appl. Microbiol. 1971, 22, 408-414. [CrossRef]

41. Abou-Elela, G.M.; Ibrahim, H.A.; Hassan, S.W.; Abd-Elnaby, H.; El-Toukhy, N.M.K. Alkaline protease production by alkaliphilic marine bacteria isolated from Marsa-Matrouh (Egypt) with special emphasis on Bacillus cereus purified protease. Afr. J. Biotechnol. 2011, 10, 4631-4642.

42. Arasu, M.V.; Duraipandiyan, V.; Agastian, P.; Ignacimuthu, S. In vitro antimicrobial activity of Streptomyces spp. ERI-3 isolated from Western Ghats rock soil (India). J. Med. Mycol. 2009, 19, 22-28. [CrossRef] 
43. Iqbal, S.; Qasim, M.; Begum, F.; Rahman, H.; Sajid, I. Screening, Characterization and Optimization of antibacterial peptides, produced by Bacillus safensis strain MK-12 isolated from waste dump soil KP, Pakistan. BioRxiv 2018. [CrossRef]

44. Rajaram, S.K.; Ahmad, P.; Keerthana, S.S.S.; Cressida, P.J.; Moorthy, I.G.; Suresh, R.S.S. Extraction and purification of an antimicrobial bioactive element from lichen associated Streptomyces olivaceus LEP7 against wound inhabiting microbial pathogens. J. King Saud Univ. Sci. 2020, 32, 2009-2015. [CrossRef]

45. Ranjan, R.; Jadeja, V. Isolation, characterization and chromatography based purification of antibacterial compound isolated from rare endophytic actinomycetes Micrococcus yunnanensis. J. Pharm. Anal. 2017, 7, 343-347. [CrossRef]

46. Selvin, J.; Shanmughapriya, S.; Gandhimathi, R.; Kiran, G.S.; Ravji, T.R.; Natarajaseenivasan, K.; Hema, T.A. Optimization and production of novel antimicrobial agents from sponge associated marine actinomycetes Nocardiopsis dassonvillei MAD08. Appl. Microbiol. Biotechnol. 2009, 83, 435. [CrossRef] [PubMed]

47. Hozzein, W.N.; Rabie, W.; Ali, M.I.A. Screening the Egyptian desert actinomycetes as candidates for new antimicrobial compounds and identification of a new desert Streptomyces strain. Afr. J. Biotechnol. 2011, 10, 2295-2301.

48. Chawawisit, K.; Bhoopong, P.; Phupong, W.; Lertcanawanichakul, M. 2,4-Di-tert-butylphenol, the bioactive compound produced by Streptomyces sp. KB1. J. Appl. Pharm. Sci. 2015, 5, 007-012. 